\title{
Prirojeni portosistemski venski obvodi
}

\section{Congenital Portosystemic Venous Shunts}

Paola Trupac, Petja Fister

\section{Izvleček}

Prirojeni portosistemski venski obvodi (PPSVO) so redka skupina heterogenih razvojnih nepravilnosti portalnega in sistemskega krvnega obtoka, zaradi katerih kri iz portalnega sistema preko različnih žilnih obvodov zaobide presnovo $v$ jetrih in teče neposredno v sistemski krvni obtok. Razdelimo jih lahko v dve skupini - znotrajjetrne, med katere uvrščamo tudi perzistentni venozni duktus, in zunajjetrne obvode. Zaradi nepravilnega toka splanhnične krvi z nerazgrajenimi presnovki neposredno v sistemski krvni obtok lahko nastanejo hudi zapleti: neonatalna holestaza, benigni in maligni jetrni tumorji, hepato-pulmonalni sindrom, portopulmonalna hipertenzija in encefalopatija. Majhni znotrajjetrni obvodi se lahko v prvih dveh letih življenja spontano umaknejo. Druge, trajne znotrajjetrne in zunajjetrne obvode moramo zapreti v enem ali dveh korakih z maloinvazivnimi intervencijskimi radiološkimi zapiralnimi metodami ali s kirurškim posegom. Pri zunanjjetrnem obvodu tipa 1 je vedno potrebna presaditev jeter.

Ključne besede: portosistemski venski obvod, znotrajjetrni obvod, zunajjetrni obvod, hepato-pulmonalni sindrom, novorojenček.

\begin{abstract}
Congenital portosystemic venous shunts (CPSS) are a rare group of heterogeneous developmental malformations of the portal and systemic circulation causing blood from the portal system to bypass liver metabolism through various vascular junctions and flow directly into the systemic circulation. They can be divided into two groups comprising intrahepatic shunts, with persistent ductus venosus, and extrahepatic shunts. The anomalous flow of splanchnic blood with undegraded metabolites directly into the systemic circulation may lead to severe complications: neonatal cholestasis, benign and malignant liver tumours, hepato-pulmonary syndrome, porto-pulmonary hypertension and encephalopathy. Small intrahepatic shunts may regress spontaneously in the first two years of life. Other permanent intrahepatic and extrahepatic shunts should be closed in one or two steps by minimally invasive interventional radiological closure methods or by surgical procedure. Extrahepatic type 1 shunts always require liver transplantation.
\end{abstract}

Key words: portosystemic shunts, intrahepatic shunt, extrahepatic shunt, hepato-pulmonary syndrome, neonate. 


\section{Uvod}

Prirojeni portosistemski venski obvod (PPSVO) je redka žilna nepravilnost portalnega in sistemskega krvnega obtoka, ki se pojavi sekundarno zaradi nenormalnega razvoja ali involucije plodovega žilja. Obvod povzroči, da kri oziroma del krvi teče iz splanhničnih organov neposredno v sistemski obtok ter tako zaobide jetra in presnovo v njih. Največkrat se PPSVO pojavi kot osamljena nepravilnost, možna je tudi hkratna prisotnost več obvodov (1). Prav tako je pri otroku s PPSVO mogoče, da ima pridružene nepravilnosti drugih organov ali genetske napake: prirojene srčne napake (defekt prekatnega pretina, defekt preddvornega pretina, odprto ovalno okno, koarktacija aorte, Fallotova tetralogija, odprt Botallov vod), kromosomopatije (Downov sindrom), redke sindrome (sindrom LEOPARD, Rendu-Osler-Weberjev sindrom), sindrom polisplenije ali kompleksne prirojene nepravilnosti (nepravilnosti ledvic, žolčevodov, prebavil, kosti ali možganov) $(1,2)$. $V$ daljšem obdobju lahko obvod povzroči različne zaplete, nekatere težke, kot so neonatalna holestaza, benigni in maligni jetrni tumorji, hepatopulmonalni sindrom, portopulmonalna hipertenzija in encefalopatija (1). V nadaljevanju prikazujemo embriološki nastanek in različne razdelitve PPSVO glede na anatomijo, prirojene napravilnosti, ki so lahko povezane s PPSVO, ter klinično sliko, diagnosticiranje in terapevtski pristop pri obravnavi bolnika s PPSVO.

\section{Embriologija}

Razvoj portalnega venskega sistema je kompleksno dogajanje, ki se odvija med 4 . in 10. tednom embrionalnega življenja (1). Venski sistem se $v$ zarodku razvija iz treh osnovnih embrioloških venskih sistemov, ki se stekajo v venski sinus parnih vitelinskih ali omfalomezenteričnih ven, ki zbirajo kri iz rumenjakove vrečke, ter parnih popkovničnih in kardinanih ven (1-4). Vitelinski veni pred vstopom $v$ venski sinus ustvarita venski pletež, ki ga prepredejo jetrni povezki, s čimer nastanejo jetrni sinusoidi. Iz desne vitelinske vene, ki jo imenujemo desni hepatokardialni kanal, nastane končni del spodnje votle vene, iz venskega pleteža okrog dvanajstnika pa portalna vena. Iz distalnega dela desne vitelinske vene se razvije zgornja mezenterična vena. Po popkovničnih venah teče kri iz posteljice skozi jetra $v$ srce. $Z$ rastjo jeter se veni povežeta $z$ jetrnimi sinusoidi, večino vse večjega dotoka krvi iz posteljice pa prevzame venski vod, ki povezuje levo popkovnično veno $z$ desnim hepatokardialnim kanalom. Po rojstvu leva popkovnična vena in venski vod zakrnita. Tako sistemski in portalni venski sistem nastaneta iz prednje in zadnje kardinalne ter obeh vitelinskih ven, medtem ko popkovni veni drenirata kri iz rumenjakove vrečke in posteljice. Če vitelinske vene $v$ času embrionalnega razvoja ne izginejo popolnoma, nastanejo PPSVO, njihov tip pa je odvisen od tega, ali desna ali leva vitelinska vena oz. trajne povezave vitelinskih venul z jetrnimi sinusoidi vztrajajo. Če venski pletež okrog dvanajstnika prekomerno zakrni, se portalna vena ne razvije. Zaradi spremenjene hemodinamike po rojstvu venski vod pri novorojenčku lahko ostane odprt in predstavlja znotrajjetrni obvod ter povzroči hipoplazijo portalne vene $(1,5)$. Pojavnost PPSVO je 1 na 30.000 rojenih otrok $(1,2)$.

\section{Razdelitev}

Različni avtorji PPSO razvrščajo na različne načine. Nekateri PPSVO delijo glede na umeščenost in obliko obvoda (6), drugi glede na umeščenost obvoda in indikacije za kirurški poseg (4). Klinično so najbolj uporabne razdelitve glede na umeščenost obvodov, tj. na znotrajjetrne in zunajjetrne obvode. Znotrajetrne PPSVO nekateri avtorji glede na stopnjo znotrajetrne portalne hipoplazije delijo na blage, zmerne in hude (7).
Znotrajjetrne obvode po Parku razdelimo v štiri tipe (8). Gre za komunikacije med znotrajjetrno portalno veno in jetrnimi ali objetrnimi venami, ki so $v$ premeru večje od enega milimetra. Med znotrajjetrne obvode uvrščamo tudi vztrajajajoči venski vod. Delimo jih na (Slika 1):

1. tip 1: ena anastomoza, ki povezuje desno vejo portalne vene s spodnjo votlo veno;

2. tip 2: periferna povezava $v$ enem jetrnem segmentu med perifernimi vejami portalne vene in jetrnimi venami;

3. tip 3: anevrizmatksa povezava med perifernimi vejami portalne vene in jetrnimi venami;

4. tip 4: številne drobne povezave difuzno po obeh jetrnih režnjih.

Zunajjetrne PPSVO po Morganu in Superini delimo $v$ dva tipa: tip 1 (t. i. Abernethyjeva malformacija 1) ali popolni obvod in tip 2 (t. i. Abernethyjeva malformacija 2) ali nepopolni obvod (Slika 2).

Tip 1. Za popolni zunajjetrni obvod je značilno, da ni vtoka portalne krvi $v$ jetra, zato se portalna vena steka neposredno $v$ spodnjo votlo veno in splanhnična kri povsem zaobide jetra: vranična in zgornja mezenterična vena se vlivata $v$ spodnjo votlo veno (tip 1A) ali vranična in zgornja mezenterična vena se preko zunajjetrne portalne vene vlivata v spodnjo votlo veno (tip 1B).

Tip 2. za nepopolni zunajjetrni obvod je značilno, da je le del portalne krvi preusmerjen $v$ sistemski obtok $z$ ohranjenim ali hipoplastičnim glavnim portalnim deblom. Nepopolne obvode nadalje po Kobayashiju (9) glede na umeščenost obvoda in povezavo z zapleti delimo $v$ tri tipe (tip A, tip B in tip C):

- tip A: splanhnična kri se vliva v spodnjo votlo veno, zato se razvijejo jetrni noduli in encefalopatija;

- tip B: splanhnična kri se vliva v ledvični veni in razvije se encefalopatija; - tip C: splanhnična kri se vliva v iliakalni veni, razvije se želodčno-črevesna krvavitev. 
Prirojene nepravilnosti, ki so lahko povezane $s$ prirojenimi portosistemskimi venskimi obvodi

S PPSVO opisujejo sopojavnost različnih prirojenih nepravilnosti številnih organov in organskih sistemov, kar prikazujemo v Tabeli 1.

\section{Klinična slika}

Klinična slika pri bolnikih s PPSVO je lahko posledica treh vzrokov (10):

1. obvoda portalne krvi s povišanimi koncentracijami vazoaktivnih mediatorjev in strupenih presnovkov, kot sta amonijev ion in galaktoza, neposredno v sistemski krvni obtok;

2. pridruženih prirojenih nepravilnosti ali

3. okvare jeter.

Raznolika klinična slika heterogene skupine bolnikov s PPSVO se lahko pokaže že intrauterino, pri novorojenčku, pri otroku ali šele v odraslosti. Pred rojstvom slikovne diagnostične metode omogočajo ugotovitev spremenjenega plodovega krvnega obtoka in zmanjšane prekrvitve jeter, ki se lahko kaže kot znotrajmaternični zastoj rasti, pri katerem ne ugotovimo drugega vzroka za hipoksijo ploda, intrauterine okužbe ali kromosomopatije (1). Pri novorojenčkih se lahko pojavita holestaza in galaktozemija, ki ju moramo razlikovati od drugih prirojenih bolezni (atrezije žolčnih vodov, presnovnih bolezni).

Kasneje v otroštvu igra spremenjen krvni obtok ključno vlogo pri nastanku kliničnih znakov ter pri razvoju zapletov. Zaradi spremenjenega toka splanhnične krvi vazoaktivni mediatorji prehajajo neposredno v sistemski krvni obtok ter povzročajo razširitev pljučnih žil in slabšo izmenjavo kisika, kar se kaže kot vztrajajoča hipoksija in hepatopulmonalni sindrom $(1,11)$. Ti otroci imajo cianozo, betičaste prste
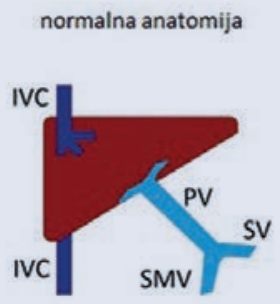

2notrajjetrni obvod tip 2

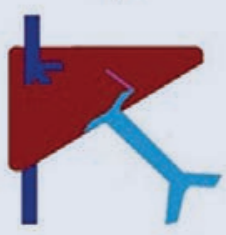

znotrajjetrni obvod tip 3

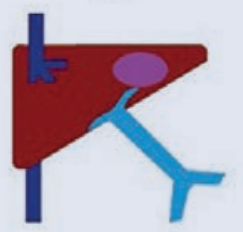

znotrajjetrni obvod tip I

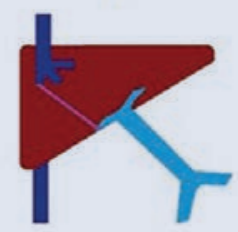

znotrajjetrni obvod tip 4

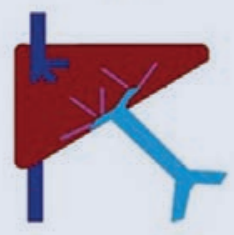

SLIKA 1. ZNOTRAJJETRNI PRIROJENI PORTOSISTEMSKI VENSKI OBVODI (PPSVO), RAZDELITEV PO PARKU. (POVZETO PO 8, 10).

Legenda: IVC - spodnja votla vena; PV - portalna vena; SMV - zgornja mezenterična vena; SV - vranična vena. FIGURE 1. INTRAHEPATIC CONGENITAL PORTOSYSTEMIC VENOUS SHUNTS (CPSS), CLASSIFICATION BY PARK. (ADAPTED FROM 8, 10).

Abbreviations: IVC-inferior vena cava; PV-portal vein; SMV-superior mesenteric vein; SV-splenic vein.

\begin{tabular}{|c|c|c|c|}
\hline Srčne napake & Nepravilnosti ožilja & Nepravilnosti sečil & Sindromi \\
\hline \multirow{5}{*}{$\begin{array}{l}\text { Defekt prekatnega ali } \\
\text { defekt preddvornega } \\
\text { pretina } \\
\text { Odprto ovalno okno } \\
\text { Prirojena zožitev } \\
\text { aortne ali } \\
\text { pulmonalne zaklopke }\end{array}$} & \multirow{2}{*}{$\begin{array}{l}\text { Dvojna spodnja votla } \\
\text { vena }\end{array}$} & \multirow{2}{*}{$\begin{array}{l}\text { Agenezija ledvic ali } \\
\text { cistična displazija } \\
\text { ledvic }\end{array}$} & \multirow{4}{*}{$\begin{array}{l}\text { Downov } \\
\text { Turnerjev } \\
\text { Leopardov } \\
\text { Rendu-Osler-Weberjev }\end{array}$} \\
\hline & & & \\
\hline & $\begin{array}{l}\text { Levostranska spodnja } \\
\text { votla vena }\end{array}$ & 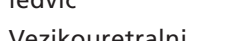 & \\
\hline & \multirow{2}{*}{$\begin{array}{l}\text { Nadaljevanje } \\
\text { v. azygos in } \\
\text { v. hemiazygos }\end{array}$} & refluks & \\
\hline & & $\begin{array}{l}\text { Združena križna } \\
\text { ektopična ledvica }\end{array}$ & $\begin{array}{l}\text { Bannayan-Riley- } \\
\text { Ruvalcaba }\end{array}$ \\
\hline \multirow{5}{*}{$\begin{array}{l}\text { Tetralogija Fallot } \\
\text { Trikuspidna atrezija } \\
\text { Mitralna atrezija }\end{array}$} & Kožni hemangiomi & Hipospadija & Holt-Oramov \\
\hline & \multirow{2}{*}{$\begin{array}{l}\text { Anevrizme vranične } \\
\text { arterije }\end{array}$} & & Graziolijev \\
\hline & & & Goldenharjev \\
\hline & $\begin{array}{l}\text { Fistule koronarnih } \\
\text { arterij }\end{array}$ & & \\
\hline & $\begin{array}{l}\text { Primitivna } \\
\text { hipoglosalna arterija }\end{array}$ & & \\
\hline $\begin{array}{l}\text { Nepravilnosti } \\
\text { trebušnih organov }\end{array}$ & Nepravilnosti prebavil & & \\
\hline Atrezija žolčnih vodov & Juvenilna polipoza & & \\
\hline Polisplenija & Atrezija dvanajstnika & & \\
\hline \multirow[t]{2}{*}{ Situs inversus } & Mreža dvanajstnika & & \\
\hline & $\begin{array}{l}\text { Obročasta trebušna } \\
\text { slinavka }\end{array}$ & & \\
\hline
\end{tabular}

TABELA 1. PRIROJENE NEPRAVILNOSTI, KI SO POVEZANE S PRIROJENIMI PORTOSISTEMSKIMI VENSKIMI SPOJI. POVZETO PO PAPAMICHAIL ET AL (1).

TABLE 1. CONGENITAL ABNORMALITIES CONNECTED WITH CONGENITAL PORTOSYSTEMIC VENOUS SHUNTS. ADAPTED FROM PAPAMICHAIL ET AL (1). 


\section{Abernethy tip 1}

zunajjetrni obvod

tip la

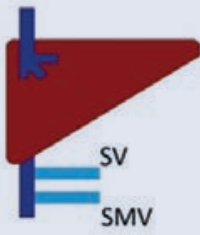

zunajjetrni obvod tip A

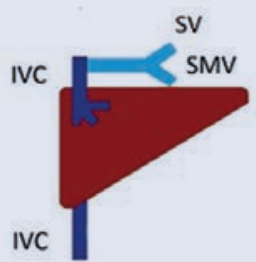

zunajjetrni obvod tip lb

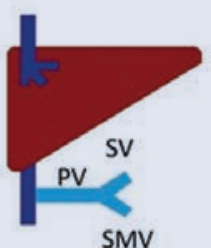

zunajjetrni obvod tip B

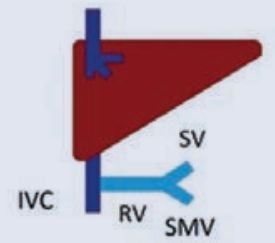

Abernethy tip 2

zunajjetrni obvod tip II

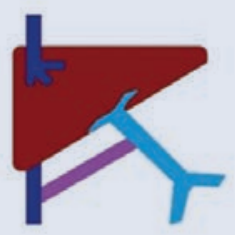

zunajjetrni obvod tip C

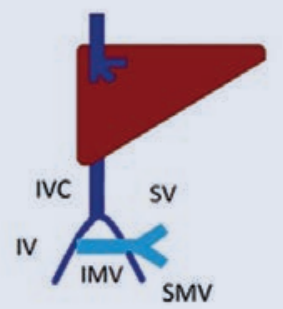

SLIKA 2. ZUNAJJETRNI PRIROJENI PORTOSISTEMSKI VENSKI OBVODI (PPSVO), RAZDELITEV PO MORGANU IN SUPERINI TER RAZDELITEV PO KOBAYASHIJU (TIP A, TIP B IN TIP C). (POVZETO PO 7,10). Legenda: IVC - spodnja votla vena; PV - portalna vena; SMV - zgornja mezenterična vena; IMV - spodnja mezenterična vena; SV - vranična vena; RV - ledvična vena (leva ali desna).

FIGURE 2. EXTRAHEPATIC CONGENITAL PORTOSYSTEMIC VENOUS SHUNTS (CPSS), CLASSIFICATION BY MORGAN AND SUPERINA AND CLASSIFICATION BY KOBAYASHI (TYPE A, TYPE B, TYPE C). (ADAPTED FROM 7, 10)

Abbreviations: IVC-inferior vena cava; PV-portal vein; SMV-superior mesenteric vein; IMV-inferior mesenteric vein; SV-splenic vein; RV-renal vein (left or right).

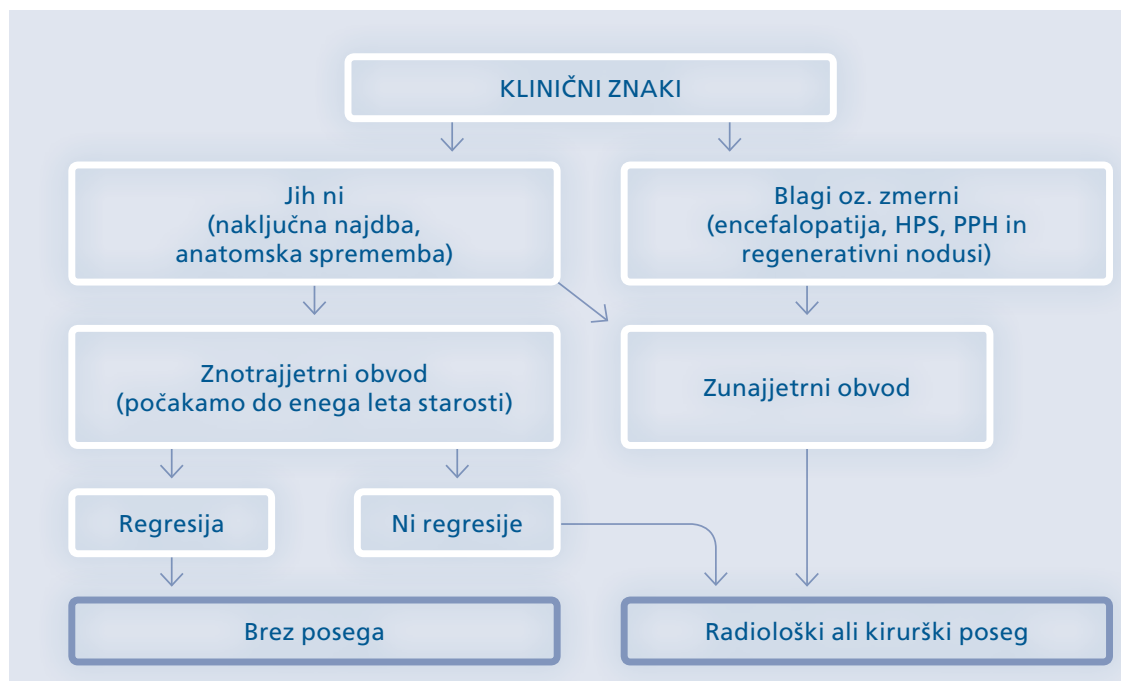

SLIKA 3. ALGORITEM VODENJA OTROKA S PRIROJENIM PORTOSISTEMSKIM VENSKIM SPOJEM (PPSVO). POVZETO PO PAPAMICHAIL ET AL (1).

Legenda: HPS - hepatopulmonalni sindrom; PPH - portopulmonalna hipertenzija.

FIGURE 3. ALGORITHM FOR THE MANAGEMENT OF A CHILD WITH CONGENITAL PORTOSYSTEMIC VENOUS SHUNTS (CPSS). ADAPTED FROM PAPAMICHAIL ET AL. (1).

Abbreviations: HPS- hepato-pulmonary syndrome; $\mathrm{PPH}$ - porto-pulmonary hypertension. in dispnejo, najprej ob naporu, kasneje že v mirovanju. V sistemski krvi je zaradi obvoda splanhnične krvi neposredno v sistemski krvni obtok zvišana tudi koncentracija amonijevega iona $(1,6)$. Dolgotrajni PPSVO zaradi hiperamonemije in drugih strupenih presnovkov povzročijo nastanek zapletov na osrednjem živčevju in pljučih, t. i. hepatično encefalopatijo in hepatopulmonalni sindrom. Otroci s hepatopulmonalnim sindromom zaradi PPSVO lahko kasneje razvijejo portopulmonalno hipertenzijo. Histološko ugotovijo mikrotrombe in fibrozo intime pljučnih arterij. Porto-pulmonalno hipertenzijo v sklopu PPSVO navadno diagnosticiramo pozno, zato sta $v$ tem primeru tako uspešnost kirurškega zdravljenja kot tudi napoved izida bolezni neugodni. Zaradi hepatične encefalopatije imajo otroci s PPSVO lahko nevrokognitivno disfunkcijo in druge vedenjske spremembe $(1,6)$. Pridruženi klinični znaki so utrujenost, cerebralni paroksizmi in slabo pridobivanje telesne teže.

Zaradi velikih hemodinamskih sprememb na ravni jetrnega parenhima se pri $25-50 \%$ otrok s PPSVO pojavijo regenerativni nodusi, lahko tudi adenomi, žariščna nodularna hiperplazija ali hemangiomi (1). Ti so rezultat prilagoditvenega povečanja toka krvi v hepatičnih arterijah in povišanih koncentracij cirkulirajočih jetrnih rastnih dejavnikov (inzulin, glukagon, hepatocitni rastni dejavnik). Pri desetini odraslih z zunajjetrnimi PPSVO se ob odsotnosti nepravilnega delovanja jeter ali ciroze lahko pojavijo maligni tumorji (jetrnocelični karcinom, hepatoblastom, sarkom) $(1,10)$. Tumor lahko nastane na novo (primarni tumor), bolj pogosta pa je maligna transformacija benignih sprememb (regenerativnih nodusov). Zato priporočajo pogostejše klinično spremljanje teh bolnikov $(1,10)$.

Zunajjetrni PPSVO se lahko kažejo kot krvavitev prebavil: iz zgornjih prebavil (iz varic požiralnika) ali iz črevesa (iz varic kolona in rektuma, ki so močno 
razširjene zaradi zapore portalnega krvnega sistema). V literaturi opisujejo tudi redke zaplete bolezni: parkinsonizem, avtizem in spastično paraparezo, ki so posledica hiperamonemije, hiperandrogenizma s primarno amenorejo ali znaki virilizacije, hiperinzulinemijo zaradi inzulinske rezistence perifernih tkiv, pankreatitis zaradi anatomske zožitve pankreatobilarnih povezav, vaginalno krvavitev ali hematurijo zaradi hemoaragične diateze, kamne v sečilih in membranoproliferativni glomerulonefritis zaradi hkratne okvare ledvic (1).

\section{Diagnosticiranje}

Ob kliničnem sumu na prisotnost PPSVO pri bolniku opravimo meritev nasičenosti arterijske krvi s kisikom ter laboratorijske preiskave krvi in urina (3): določimo koncentracijo glukoze in amonijevega iona v krvi preprandialno in postprandialno, koncentracijo galaktoze v krvi, koagulacijske teste, koncentracije alanin aminotransferaze, aspartat aminotransferaze in gama-glutamil transferaze, serumsko koncentracijo žolčnih kislin, mangana in alfa-fetoproteina, v urinu pa določimo stopnjo hematurije in proteinurije zaradi možne okvare ledvic ob PPSVO. Za opredelitev tipa in velikosti PPSVO ter pridruženih sprememb v jetrih uporabimo radiološke slikovne metode, kot so ultrazvok trebuha z uporabo doplerja, računalniška tomografija (CT) ali magnetnoresonančno slikanje (MR) in klasična angiografija z venografijo obvodov $(1,10,12)$. Za dodatno opredelitev difuzne parenhimske okvare lahko opravimo biopsijo jeter. Za opredelitev sprememb možganovine lahko opravimo elektroencefalogram in magnetnoresonančno (MRI) slikanje glave, s katerim lahko opredelimo atrofijo bele možganovine. Za ugotavljanje pridruženih prirojenih nepravilnosti ali potencialnih zapletov moramo opraviti še usmerjene preiskave: ultrazvok srca, gastroskopijo in kolonoskopijo ter teste pljučne funkcije (1).

\section{Zdravljenje}

Cilj zdravljenja je vzpostaviti normalen portalni krvni pretok skozi jetra. Nekateri, predvsem manjši znotrajjetrni obvodi, lahko v prvih dveh letih starosti izginejo, zato lahko dojenčke in majhne otroke $v$ tem času klinično spremljamo (2). Druge, trajne znotrajjetrne in zunajjetrne obvode (razen popolnega zunajjetrnega obvoda), ki po enem do dveh letih starosti otroka vztrajajo in se kažejo s kliničnimi znaki, moramo zapreti. Zapiranje opravimo v enem ali dveh korakih z maloinvazivnimi intervencijskimi radiološkimi zapiralnimi metodami ali s kirurškim posegom, da se zapleti ne razvijejo $(1,6,11)$. Pri bolnikih brez znakov bolezni priporočajo redno spremljanje koncentracije amonijevega iona $v$ serumu in kontrolni doplerski ultrazvok, elektrokardiogram in po potrebi ultrazvok srca (6). Če je koncentracija amonijaka v krvi povišana, v zdravljenje vključimo dieto, ki je podobna kot pri bolnikih z jetrno cirozo in encefalopatijo ter obsega omejitev vnosa beljakovin in uporabo laktuloze.

Indikacije za intervencijski radiološki ali kirurški poseg so encefalopatija, hepatopulmonalni sindrom, portopulmonalna hipertenzija, veliki ali spreminjajoči se regenerativni nodusi v jetrih in povečanje velikosti obvoda $(1,12)$. Kirurško zapiranje obvoda je indicirano pri bolnikih z refraktornimi znaki (hipoksija, hiperamonemija) in pri bolnikih, pri katerih zdravljenje z zdravili (ursodeoksiholna kislina, vezalci amoniaka: natrijev benzoat, natrijev fenilacetat, natrijev fenilbutirat) ni bilo učinkovito $(1,6)$. Če je bolnik brez simptomov in znakov prisotnosti PPSVO, lahko glede na razmerje obvoda izračunamo stopnjo tveganja za nastanek encefalopatije. $Z$ doplerskim ultrazvokom izračunamo razmerje spoja tako, da primerjamo pretok krvi v obvodu in celotni portalni krvni pretok. Če razmerje presega $60 \%$, je potrebno zdravljenje (1). Pred kirurškim zapiranjem moramo izključiti možnost, da obvod ni posledica portalne hiper- tenzije ali jetrnega hemangioma, kar bi zahtevalo specifičen pristop k zdravljenju (2).

Uveljavljenih je več možnih razrešitev PPSVO. Glede na različne tipe in velikosti obvodov se radiolog ali kirurg odločata za enostopenjski ali dvostopenjski poseg (13). Izvedemo lahko znotrajžilno embolizacija s čepi ali spiralami ali kirurško ligiranje (1). Zaradi manjše stopnje invazivnosti je standard zaprtja PPSVO perkutani znotrajžilni pristop (12-14). Z balonskim okluzijskim testom ocenimo trend naraščanja portalnega tlaka po začasnem zaprtju PPSVO. Ob zanemarljivem tveganju portalne hipertenzije lahko izvedemo embolizacijo $(1,14)$. Presaditev jeter je vedno potrebna pri zunajjetrnem obvodu tipa 1 in pri nepopolnem zunajjetrnem obvodu s slabim izidom okluzijskega testa $(4,9)$, prav tako pri velikih večžariščnih znotrajjetrnih obvodih in pri večžariščnih jetrnih tumorjih (2).

\section{Zaključek}

PPSVO so redka skupina heterogenih razvojnih nepravilnosti portalnega in sistemskega krvnega obtoka, ki se lahko pokažejo kadar koli v življenju. Klinična slika je neznačilna, zapleti ob neprepoznani bolezni pa lahko težki. Z moderno tehnologijo (doplerski ultrazvok, preiskave s CT in MRI) v današnjem času diagnostično obravnavo izvedemo lažje in bolj natančno kot pred leti. Za dober izid je pomembna individualna multidisciplinarna obravnava z ustrezno postavljenim kliničnim sumom, diagnostično potrditvijo in terapevtskim načrtom.

\section{Literatura}

1. Papamichail M, Pizanias M, Heaton N. Congenital portosystemic venous shunt. Eur J Pediatr 2018; 177: 285-94.

2. Bernard O, Franchi-Abella S, Branchereau S, Pariente D, Gauthier F, Jacquemin E. Congenital portosystemic shunts in children: recognition, 
evaluation, and management. Semin Liver Dis 2012; 32: 273-87.

3. Plut D, Gorjanc T. A case of a newborn with an intrahepatic congenital portosystemic venous shunt with concurrent congenital duodenal web. Acta Radiol Open 2019; 8: 1-4.

4. Blanc T, Guerin F, Franchi-Abella S, Jacquemin E, Pariente D, Soubrane O et al. Congenital portosystemic shunts in children: a new anatomical classification correlated with surgical strategy. Ann Surg 2014; 260: 188-98.

5. Hikspoors JPJM, Peeters MMJP, Mekonen HK, Kruepunga N, Mommen GMC, Cornillie P et al. The fate of the vitelline and umbilical veins during the development of the human liver. J Anat 2017; 231: 718-35.

6. Lautz TB, Tantemsapya N, Rowell E, Superina RA. Management and classification of type II congenital portosystemic shunts. J Pediatr Surg 2011; 46: 308-14.

7. Kanazawa H, Nosaka S, Miyazaki O, Sakamoto S, Fukuda A, Shigeta T et al. The classification based on intrahepatic portal system for congenital portosystemic shunts. J Pediatr Surg 2015; 50 : 688-95.

8. Park JH, Cha SH, Han JK, Han MC. Intrahepatic portosystemic venous shunt. AJR Am J Roentgenol 1990; 155: 527-8.

9. Kobayashi N, Niwa T, Kirikoshi H, Fujita K, Yoneda M, Saito S, et al. Clinical classification of congenital extrahepatic portosystemic shunts. Hepatol Res 2010; 40: 585-93.

10. Ghuman SS, Gupta S, Buxi TBS, Rawat KS, Yadav A, Mehta N et al. The Abernethy malformation-myriad imaging manifestations of a single entity. 2016. Indian J Radiol Imaging 2016; 26: 364-72.

11. Kamata S, Kitayama Y, Usui N, Kuroda S, Nose K, Sawai T et al. Patent ductus venosus with a hypoplastic intrahepatic portal system presenting intrapulmonary shunt: a case treated with banding of the ductus venosus. J Pediatr Surg 2000; 35: 655-7.

12. Lee SA, Lee YS, Lee KS, Jeon GS. Congenital intrahepatic portosystemic venous shunt and liver mass in a child patient: successful endovascular treatment with an amplatzer vascular plug (AVP). Korean J Radiol 2010; 11: 583-6.

13. Chun PT, Chun T, Files M, Vo N, Adams RM Percutaneous embolization of congenital portosystemic venous fistula in infant with Down syndrome. Case Rep Vasc Med 2013; 2013 : 127023.

14. Timpanaro T, Passanisi S, Sauna A, Trombatore C, Pennisi M, Petrillo G et al. Congenital portosystenic shunt: Our experience. Case Rep Pediatr 2015; 2015: 691618. doc. dr. Petja Fister, dr. med (kontaktna oseba/contact person) Klinični oddelek za neonatologijo, Pediatrična klinika, Univerzitetni klinični center in

Katedra za pediatrijo, Medicinska

fakulteta Ljubljana

Bohoričeva ulica 20, 1000 Ljubljana,

Slovenija

e-naslov: petja.fister@kclj.si

Paola Trupac, dr. med.

Zdravstveni dom Koper, Koper, Slovenija

prispelo / received: 22. 8.2020

sprejeto / accepted: 16. 1. 2021

Fister P, Trupac P. Prirojeni portosistemski venski obvodi. Slov Pediatr 2021; 28(1): 10-15. https:// doi.org/10.38031/slovpediatr-2021-1-02. 